\title{
Role of Dendritic Epidermal T Cells in Cutaneous Carcinoma
}

\author{
Jian Xiang ${ }^{\dagger}$, Minghui Qiu ${ }^{\dagger}$ and Hongyi Zhang* \\ Department of Microbiology and Immunology, School of Medicine, Jinan University, Guangzhou, China
}

\section{OPEN ACCESS}

Edited by:

Deborah A. Witherden,

The Scripps Research Institute,

United States

Reviewed by:

Carrie R. Willcox,

University of Birmingham,

United Kingdom

Tomasz Zal,

University of Texas MD Anderson

Cancer Center, United States

*Correspondence:

Hongyi Zhang

hongyizhang@jnu.edu.cn

†These authors have contributed equally to this work

Specialty section: This article was submitted to $T$ Cell Biology,

a section of the journal

Frontiers in Immunology

Received: 21 February 2020 Accepted: 19 May 2020

Published: 14 July 2020

Citation:

Xiang J, Qiu M and Zhang H (2020) Role of Dendritic Epidermal T Cells in

Cutaneous Carcinoma.

Front. Immunol. 11:1266.

doi: 10.3389/fimmu.2020.01266
Dendritic epidermal T cells (DETCs) are $\gamma \delta T$ cells expressing invariant $V_{\gamma} 5 \mathrm{~V} \delta 1 \mathrm{~T}$ cell receptor (TCR) in murine epidermis. Initially, the development and the maturation of DETC progenitors are mediated by skint-1, TCR, and cytokines in the fetal thymus. Then, the DETC progenitors migrate to the epidermis with the guidance of selectins, CCR10, CCR4, etc. Eventually, mature DETCs proliferate and maintain a homeostatic population in the epidermis through IL-15 and aryl hydro-carbon receptor signaling. In "stressed" skin, DETCs are activated, exhibiting features such as a round morphology, cytotoxicity, and production of cytokines. In cutaneous carcinoma, DETCs generally inhibit tumor development directly in non-major histocompatibility complex-restricted manner, with the assistance of cytokines. DETCs also recognize and inhibit tumor via TCR, non-TCR receptors (such as 2B4 and NKG2D), or both. This study summarizes the biogenesis and the function of DETCs in cutaneous carcinoma and clarifies the essential surveillance role in the epidermis that DETCs play. As there are no DETCs in human epidermis but only human epidermis $\gamma \delta$ T cells, we need to understand the anti-tumor pathways used by DETCs to find analogous immune pathways in human skin, which could be exploited for novel therapeutics.

Keywords: dendritic epidermal T cells, $\gamma \delta$ T cells, epidermis, squamous cell carcinoma, melanoma

\section{INTRODUCTION}

The $\gamma \delta \mathrm{T}$ cells are abundant in epithelial surfaces of the skin, intestine, lung, etc. (1). The skin is comprised of the epidermis, the basement membrane, and the dermis. The epidermis consists of 95\% keratinocytes and 5\% immune cells, including Langerhans cells and $\mathrm{T}$ cells that are predominantly epidermal $\gamma \delta \mathrm{T}$ cells $(2,3)$. The dermis contains dermal $\gamma \delta \mathrm{T}$ cells and variant immune cells, including $\alpha \beta \mathrm{T}$ cells, macrophages, dendritic cells, etc. The epidermal $\gamma \delta \mathrm{T}$ cells are different from the dermal $\gamma \delta \mathrm{T}$ cells in the T cell receptor (TCR) chains and shapes. In mouse, compared with the round dermal $\gamma \delta \mathrm{T}$ cells expressing $\mathrm{V} \gamma 4, \mathrm{~V} \gamma 2$ but not $\mathrm{V} \gamma 5$ TCR (4), the epidermal $\gamma \delta \mathrm{T}$ cells are dendritic and exclusively express $\mathrm{V} \gamma 5 \mathrm{TCR}$, therefore termed as dendritic epidermal $\gamma \delta$ T cells (DETCs). This dendritic morphology of DETCs may be localization specific as the skin-resident memory $\mathrm{CD} 8^{+} \mathrm{T}$ cells are also dendritic in the epidermis $(3,5)$. The dendritic morphology of DETCs may be shaped by CD103 and E-cadherin $(6,7)$.

DETCs are unique in rodents, and similar $\gamma \delta \mathrm{T}$ cells reside in the epidermis of some species (8), and DETCs are reported to play an important role in wound healing and surveillance on tumors (8). In rat epidermis, the majority of T cells are dendritic $\gamma \delta \mathrm{T}$ cells, with $\mathrm{V} \gamma$ and $\mathrm{V} \delta$ chains highly similar 
to DETCs (9). In cattle epidermis, the skin-resident $\gamma \delta \mathrm{T}$ cells are still dendritic but with different $\mathrm{V} \gamma$ chain and $\mathrm{V} \delta$ chain compared with DETCs (10). In humans, the $\gamma \delta$ T cells equivalent to DETCs are to be discovered; only a small subset of $\gamma \delta \mathrm{T}$ cells expressing the V $\delta 1$ TCR reside in the epidermis, termed as human epidermal $\gamma \delta \mathrm{T}$ cells. The human epidermal $\gamma \delta$ $\mathrm{T}$ cells also promote wound healing by secreting insulin-like growth factor 1 and are also cytotoxic to cutaneous carcinoma as DETCs (11-13). However, the human epidermal $\gamma \delta \mathrm{T}$ cells are still different from DETCs in terms of the molecular mechanisms of homing to the epidermis, activation, and antigen recognition $(14,15)$, and human epidermal $\gamma \delta \mathrm{T}$ cells are round in morphology instead of dendritic. In this study, we summarize the biogenesis of DETCs and their function roles in cutaneous carcinoma and hope that these mechanisms can provide cues to the study of human epidermal $\gamma \delta \mathrm{T}$ cells in parallel.

\section{BIOGENESIS OF DETC}

DETCs are derived from DETC progenitors that are the first $\mathrm{T}$ cells generated in the thymus at embryonic day 13 (8). A few mechanisms are reported about the development and the maturation of the DETC progenitors. Skint-1, a member of the butyrophilin-like (Btnl) family proteins derived from mature thymic epithelial cells with activated rank signaling (16), is identified as the key molecule in promoting the selective development of $\mathrm{V} \gamma 5^{+}$DETC progenitors (17). Skint1 determines the differentiation direction of fetal thymocytes through a CDR3-like loop-dependent manner (17). After receiving the Skint-1 signal, the DETC progenitors provoke differentiation and produce IFN- $\gamma$ by activating the Egr3mediated pathway while suppressing Sox13 and ROR $\gamma \mathrm{t}$ that are essential for other $\gamma \delta \mathrm{T}$ cells that produce IL-17 (18). Although Skint- 1 is not a $\gamma \delta$ TCR ligand, the Skint-1-mediated selection might be through a TCR-related manner because Egr3, Sox13, and Rorc are downstream molecules of TCR signaling (18). TCR-ligands interaction is also essential for the maturation of DETC progenitors. TCRs induce the expression of sphingosine-1-phosphate receptor 1 in DETC progenitors (19). The downstream of TCR signaling in mice only have a delayed DETC accumulation but not any effect on the DETC compartment in the epidermis (20). Therefore, the TCRligands signaling might only regulate the development of DETC progenitors in the thymus. Besides the cell-cell communication, the cytokines derived from fetal thymocytes promote the development of DETC precursors. IL-7 and IL-7R signaling is essential for TCR gene transcription in a JAK/STAT pathwaydependent manner (21). IL-2 and IL-15 promote the survival of DETC precursors (21).

DETCs are located in the basal layer of the epidermis. Therefore, DETC precursors need to migrate from the thymus to the epidermis via the following steps: (1) adhering to the endothelial capillary in the dermis and (2) extravasation and locating to the epidermis (22). For the first step, DETC precursors express ligands to bind to the selectins expressed on the vascular endothelium. Although the exact ligands have not been identified, evidences show that DETCs are dramatically reduced in mice lacking E-selectins and P-selectins (23). For the second step, the DETC precursors express high levels of CC-chemokine receptor 10 (CCR10), which is the receptor of CC-chemokine ligand 27 expressed by keratinocytes (24). DETCs are markedly reduced in mice lacking CCR10 because the DETC precursors are halted in the dermis (25). A small subset of DETC precursors is homing to the epidermis in a CCR4-dependent manner (23). The $\mathrm{V} \gamma 5$ TCRs might be important for the DETC precursor migration and epidermal localization (20); however, TCR is also reported to be not specific for DETC migration and homing to the epidermis. Further investigations are needed (26-28).

Once the DETCs home in the epidermis, they proliferate exponentially along with the growth of the skin after birth in an IL-15-dependent manner as DETCs are decreased in IL-15- or IL-15R-deficient mice, while IL-15 is secreted by keratinocytes (29). In adults, DETCs are not supplied by circulating $\gamma \delta \mathrm{T}$ cells from hematopoietic stem cell but keep a homeostatic number by self-renewal in an aryl hydro-carbon receptor (AHR)-dependent manner. The AHRs are activated by ligands from the DETC cytoplasm. When lacking the AHR signaling, the DETCs cannot proliferate after homing in the epidermis (30). DETCs also produce insulin-like growth factors (IGFs) to prevent themselves from apoptosis (13). The $\mathrm{V} \gamma 5$ TCR is important for the homeostatic maintenance of mature DETCs in adults (31). Therefore, after homing to the epidermis, the mature DETCs proliferate and maintain a homeostatic population.

DETCs need to be activated to play a functional role in damaged skin and cancer. In steady-state skin, DETCs extend their dendrites to the suprabasal layers and closely contact with keratinocytes (32). In pathological-state skin, activated DETCs become motile by losing the dendrites (32). DETCs may be activated by co-culturing with transformed keratinocytes and protect keratinocytes from apoptosis in an IGF1-dependent manner $(13,33)$. The TCRs are essential for DETC activation by recognizing antigens from keratinocyte or Langerhans cells $(34,35)$. Damaged or stressed keratinocytes express TCR ligands that can activate DETCs in a non-major histocompatibility complex (MHC)-restricted manner (35-37). Beyond TCR, the complete activation of DETCs requires co-stimulatory signals such as junctional adhesion molecule-like (JAML) (38), CD100 (39), 2B4 (40), and natural killer group 2D (NKG2D) (41). JAML expressed in DETC is similar to CD28/B7 in $\alpha \beta$ T cell (38). CD100 expressed in DETC is a receptor for plexin B2-mediated signaling in keratinocyte to initiate DETC activation, with a morphology change (39). 2B4 expressed in DETC is associated with tumor target recognition (40). NKG2D expressed in DETC is a receptor for stress-induced proteins to activate DETC in responding to tumor or cutaneous wound $(42,43)$. The cytokines are also important for DETC activation. DETCs freshly isolated from skin can be activated by IL-2 (40), and activated DETCs produce IL2 (44). IL-7 and IL-15 from keratinocytes and fibroblast activate DETCs (45-47). In contrast, the activation of DETCs is inhibited by the E-cadherin of keratinocytes (7). The DETC expression of JAML (38), CD100 (39), and NKG2D (43) are critical for 
wound healing. The DETC expression of 2B4 (40), NKG2D $(41,42)$, and IL-2 (44) may facilitate the cytotoxic potential to tumor cells.

\section{ROLE OF DETC IN CUTANEOUS CARCINOMA}

A total of $90 \%$ of cutaneous carcinomas are comprised of basal cell carcinoma (BCC), squamous cell carcinoma (SCC), and melanoma. In general, the inhibition of cutaneous carcinoma by activated DETCs relies on three consecutive signals: TCR in MHC-restriction independent (15), non-TCR receptors such as NKG2D (48), 2B4 (40), or cytokines such as IL-2 (44), and IFN $\gamma$ $(38,48,49)$.

\section{DETC in Non-melanoma Skin Cancer}

BCC and SCC are usually categorized as non-melanoma skin cancer (50). BCC is the most common skin cancer, which starts from the base cell layer of the epidermis. SCC is the second common cutaneous carcinoma from damaged keratinocytes (50, 51). The non-melanoma skin cancer may be caused by solar UV radiation or chemicals such as arsenic $(52,53)$.

Majority of BCCs and 50\% of SCCs are caused by solar $\mathrm{UV}$ radiation. In chronic UV radiation, the DNA repairing mechanism caused gene mutation and genome instability, which are responses for tumor formation. PTCH1 and P53 mutations drive BCC and SCC initiation, respectively $(54,55)$. DETC is the major antitumor player in murine epidermis. DETC can directly lyse the SCC cell line Pam 212 monolayer effectively (56) or inhibit the tumor cells by inducing CD8+T cells (57). DETC can lyse the PDV tumorigenic keratinocyte cell line (42) but not the normal keratinocyte cells in vitro (56). Therefore, the DETC's cytolytic activity may be tumor cell specific. The DETCs protect the keratinocyte from UV-caused DNA damage by reducing $\gamma \mathrm{H} 2 \mathrm{AX}$, a cyclobutane pyrimidine dimer. UVdamaged keratinocytes secrete IL- $1 \beta$, which triggers DETCs to produce IL-17A, and in turn, IL-17A upregulates molecules linked to DNA repair response and limits $\gamma \mathrm{H} 2 \mathrm{AX}$ expression in keratinocyte cells (58). The DETC population is decreased in UV-irradiated epidermis (57). Therefore, DETCs might have a potential role in preventing UV-induced skin cancer, and further studies are needed. However, IL-17A plays a dual role in promoting both tumor growth and antitumor immunity in skin cancer. On one hand, IL-17A accelerates the proliferation of skin epithelial cells to promote tumorigenesis $(59,60)$. IL17A also promotes the tumor microenvironment formation by attracting an infiltration of immune cells (61). In murine models of ovarian cancer and pancreatic ductal adenocarcinoma, the IL-17-producing $\gamma \delta \mathrm{T}$ cells (not DETCs) are proliferative, active, and may directly inhibit adaptive antitumor immunity by producing PD-L1 and Galectin-9 $(62,63)$. Whether the tumorinfiltrating immune cells together with DETCs can promote tumorigenesis and tumor progression needs to be investigated. On the other hand, the IL-17-producing $\mathrm{CD}^{+} \mathrm{T}$ induces tumor regression in mice with vascularized B16 melanoma (64). The IL-17-producing $\gamma \delta \mathrm{T}$ cells enhance chemotherapy to mice with fibrosarcoma (65). Th17 cells activate endogenous cytotoxic $\mathrm{CD}^{+}{ }^{+} \mathrm{T}$ cells, leading to tumor regression in melanoma (66). The generation of IL-17-producing T cells with different phenotypes in response to variant tumor contexts would explain the conflicting observations. Whether IL-17 plays a role in DETC-mediated antitumor immunity needs to be studied. In an UV-induced SCC model, DETCs can inhibit the activation of $\mathrm{CD}^{+} \mathrm{T}$ cells, but not $\mathrm{CD} 8^{+} \mathrm{T}$ cells, within 3 days after $\mathrm{UV}$ radiation, resulting in an accelerated tumor growth (67).

Aside from UV, SCC may also be induced by chemicals. In a 7,12-dimethylbenz(a)anthracene (DMBA)/12-Otetradecanoylphorbol-13-acetate (TPA)-induced SCC model, the DETCs show an anti-tumor role as $\gamma \delta$ T-depleted mice are more acceptable for tumors than the wild-type mice. DETCs eliminate DMBA/TPA-induced SCC by expressing IFN $\gamma$ and NKG2D, therefore promoting the therapeutic effect of rapamycin on SCC (68). IFN $\gamma$ promotes the migration, activation, and cytotoxicity of DETCs in SCC. NKG2D, a receptor of natural killer cells, is only expressed in DETC in murine epidermis. The expression of ligands for NAG2D, such as Rae-1 and H60, is inducible in SCC by DMBA/TPA treatment (42). Blocking NKG2D can inhibit DETC activation, but whether these ligands activate DETCs directly or indirectly needs more investigation. Rae-1 can activate DETCs directly without TCR signaling $(69,70)$. H60c can directly activate DETCs to produce IL-13 (71), but H60c is also reported to only provide co-stimulatory signals for DETC activation, failing to activate DETCs directly $(69,72)$. Thus, DETCs eliminate tumor mediated by NKG2D, but the NKG2D signaling of DETCs may response differently in a different stimulation content.

Cutaneous lymphoma, a rare subtype of non-Hodgkin lymphoma, starts from the lymphocytes in the skin but is not classified as cutaneous carcinoma. As for the well-established non-Hodgkin lymphoma cell line YAC, DETCs directly kill YAC cells by producing perforin and granzymes (56), and this cytotoxicity is not MHC-restricted $(73,74)$. The anti-tumor potential of DETCs is strengthened in the presence of cytokines. 2B4, initially found in $\mathrm{NK}$ cells and $\mathrm{T}$ cells, associate with non-MHC-restricted recognition to tumor targets $(75,76)$, is expressed in DETC, and mediates the killing of tumor cells by DETC (40). IL-2 enhances the cytotoxicity of DETC to lymphoma cells by stimulating 2B4 expression (40). The DETCs activated by CoA produce IL-2, which stimulates DETCs to kill YAC cells $(40,44)$. IL-7, produced by keratinocytes, is also critical for DETC activation to acquire a cytotoxic capability to lymphomas (56). The cytotoxicity of DETC directly to lymphoma cells can be strengthened by cytokines.

\section{DETC in Melanoma}

Melanoma starts from melanocytes and is very aggressive and metastatic. Melanoma occupies $1 \%$ of cutaneous carcinoma cases but is the most lethal event in a cutaneous carcinoma patient. DETC cell line AU16 inhibits melanoma progression in vivo and kills melanoma cells in cytotoxicity in vitro (77). The DETC cell line AU16, derived from $\mathrm{C} 3 \mathrm{H}$ mice, is an IL-2-dependent cell line and cytotoxic to melanoma cell lines and chemo-induced fibrosarcoma in vitro (77). The injection of mixed AU16 cells 
and melanoma cells can delay the melanoma growth in vivo (77). In another study, the inhibition of DETCs to melanoma may be tumor specific as normal keratinocytes are not affected (56). The inhibition of DETCs on melanoma is IL-2 dependent and needs a close contact between DETCs and melanoma (56). Microscopically, DETCs destruct melanoma monolayers by adhering to tumor cells first and then gradually forming enlarged discrete foci to disrupt the melanoma cells. DETCs may inhibit melanoma in a NKG2D-dependent manner as NKG2D ligands are largely expressed in melanoma (78). The studies of DETCs on inhibiting melanoma are limited, and further investigations are needed.

\section{CONCLUSION AND PERSPECTIVE}

DETCs are the resident $\gamma \delta$ T cells, with a dendritic morphology, in murine epidermis. Once the skin is damaged or has tumor, DETCs are activated by cytokines (such as IL-17, IL-15, and IL-2) or signaling directly from keratinocytes and Langerhans cells. The activated DETCs generally inhibit tumor progress but also promote tumor development in a certain tumor

\section{REFERENCES}

1. Chien YH, Meyer C, Bonneville M. $\gamma \delta \mathrm{T}$ cells: first line of defense and beyond. Annu Rev Immunol. (2014) 32:121-55. doi: 10.1146/annurev-immunol-032713-120216

2. Nguyen AV, Soulika AM. The dynamics of the skin's immune system. Int J Mol Sci. (2019) 20:1811. doi: 10.3390/ijms20081811

3. Zaid A, Mackay LK, Rahimpour A, Braun A, Veldhoen M, Carbone FR, et al. Persistence of skin-resident memory T cells within an epidermal niche. Proc Natl Acad Sci USA. (2014) 111:5307-12. doi: 10.1073/pnas.1322292111

4. Sumaria N, Roediger B, Ng LG, Qin J, Pinto R, Cavanagh LL, et al. Cutaneous immunosurveillance by self-renewing dermal $\gamma \delta$ T cells. J Exp Med. (2011) 208:505-18. doi: 10.1084/jem.20101824

5. Hayday A, Tigelaar R. Immunoregulation in the tissues by $\gamma \delta \mathrm{T}$ cells. Nat Rev Immunol. (2003) 3:233-42. doi: 10.1038/nri1030

6. Schon MP, Schon M, Parker CM, Williams IR. Dendritic epidermal T cells (DETC) are diminished in integrin alphaE(CD103)-deficient mice. J Invest Dermatol. (2002) 119:190-3. doi: 10.1046/j.1523-1747.2002.17973.x

7. Uchida Y, Kawai K, Ibusuki A, Kanekura T. Role for E-cadherin as an inhibitory receptor on epidermal $\gamma \delta$ T cells. J Immunol. (2011) 186:6945-54. doi: 10.4049/jimmunol.1003853

8. Sutoh Y, Mohamed RH, Kasahara M. Origin and evolution of dendritic epidermal $\mathrm{T}$ cells. Front Immunol. (2018) 9:1059. doi: 10.3389/fimmu.2018.01059

9. Elbe A, Kilgus O, Hunig T, Stingl G. T-cell receptor diversity in dendritic epidermal $\mathrm{T}$ cells in the rat. J Invest Dermatol. (1994) 102:74-9. doi: 10.1111/1523-1747.ep12371735

10. Hein WR, Dudler L. TCR gamma delta + cells are prominent in normal bovine skin and express a diverse repertoire of antigen receptors. Immunology. (1997) 91:58-64. doi: 10.1046/j.1365-2567.1997.00224.x

11. Toulon A, Breton L, Taylor KR, Tenenhaus M, Bhavsar D, Lanigan C, et al. A role for human skin-resident T cells in wound healing. J Exp Med. (2009) 206:743-50. doi: 10.1084/jem.20081787

12. Pang DJ, Neves JF, Sumaria N, Pennington DJ. Understanding the complexity of $\gamma \delta$ T-cell subsets in mouse and human. Immunology. (2012) 136:283-90. doi: 10.1111/j.1365-2567.2012.03582.x

13. Sharp LL, Jameson JM, Cauvi G, Havran WL. Dendritic epidermal T cells regulate skin homeostasis through local production of insulin-like growth factor 1. Nat Immunol. (2005) 6:73-9. doi: 10.1038/ni1152 microenvironment. However, our understanding of the biology of DETCs is still largely limited, particularly in the area of DETCs responding to a skin tumor microenvironment. How do the DETCs maintain hemostasis in a skin tumor microenvironment? How do the DETCs communicate with the tumor-infiltrated immune cells and with the neighbor cells in the epidermis? We need to understand the anti-tumor pathways used by DETCs to find analogous immune pathways in human skin which could be exploited for novel therapeutics.

\section{AUTHOR CONTRIBUTIONS}

JX participated in the design of this study and organized the manuscript. MQ wrote the draft of the manuscript. HZ designed and revised the manuscript. All authors contributed to the article and approved the submitted version.

\section{FUNDING}

This work was supported by the Natural Science Foundation of Guangdong Province (2019A1515011966).

14. Davey MS, Willcox CR, Baker AT, Hunter S, Willcox BE. Recasting human V 11 lymphocytes in an adaptive role. Trends Immunol. (2018) 39:446-59. doi: 10.1016/j.it.2018.03.003

15. Adams EJ, Gu S, Luoma AM. Human gamma delta $T$ cells: evolution and ligand recognition. Cell Immunol. (2015) 296:31-40. doi: 10.1016/j.cellimm.2015.04.008

16. Roberts NA, White AJ, Jenkinson WE, Turchinovich G, Nakamura K, Withers $\mathrm{DR}$, et al. Rank signaling links the development of invariant gammadelta T cell progenitors and Aire (+) medullary epithelium. Immunity. (2012) 36:427-37. doi: 10.1016/j.immuni.2012.01.016

17. Salim M, Knowles TJ, Hart R, Mohammed F, Woodward MJ, Willcox CR, et al. Characterization of a putative receptor binding surface on skint-1, a critical determinant of dendritic epidermal t cell selection. J Biol Chem. (2016) 291:9310-21. doi: 10.1074/jbc.M116.722066

18. Turchinovich G, Hayday AC. Skint-1 identifies a common molecular mechanism for the development of interferon- $\gamma$-secreting versus interleukin-17-secreting $\gamma \delta \mathrm{T}$ cells. Immunity. (2011) 35:59-68. doi: 10.1016/j.immuni.2011.04.018

19. Xiong N, Kang C, Raulet DH. Positive selection of dendritic epidermal gammadelta $\mathrm{T}$ cell precursors in the fetal thymus determines expression of skin-homing receptors. Immunity. (2004) 21:121-31. doi: 10.1016/j.immuni.2004.06.008

20. Xia M, Qi Q, Jin Y, Wiest DL, August A, Xiong N. Differential roles of IL 2 -inducible T cell kinase-mediated TCR signals in tissue-specific localization and maintenance of skin intraepithelial T cells. J Immunol. (2010) 184:680714. doi: 10.4049/jimmunol.1000453

21. Ye SK, Maki K, Lee HC, Ito A, Kawai K, Suzuki H, et al. Differential roles of cytokine receptors in the development of epidermal gamma delta T cells. $J$ Immunol. (2001) 167:1929-34. doi: 10.4049/jimmunol.167.4.1929

22. Nielsen MM, Witherden DA, Havran WL. $\gamma \delta$ T cells in homeostasis and host defence of epithelial barrier tissues. Nat Rev Immunol. (2017) 17:733-45. doi: $10.1038 /$ nri.2017.101

23. Jiang X, Campbell JJ, Kupper TS. Embryonic trafficking of gammadelta T cells to skin is dependent on E/P selectin ligands and CCR4. Proc Natl Acad Sci USA. (2010) 107:7443-8. doi: 10.1073/pnas.0912943107

24. Jin Y, Xia M, Saylor CM, Narayan K, Kang J, Wiest DL, et al. Cutting edge: Intrinsic programming of thymic gammadeltaT cells for specific peripheral tissue localization. J Immunol. (2010) 185:7156-60. doi: 10.4049/jimmunol.1002781 
25. Jin Y, Xia M, Sun A, Saylor CM, Xiong N. CCR10 is important for the development of skin-specific $\gamma \delta \mathrm{T}$ cells by regulating their migration and location. J Immunol. (2010) 185:5723-31. doi: 10.4049/jimmunol.1001612

26. Hara H, Kishihara K, Matsuzaki G, Takimoto H, Tsukiyama T, Tigelaar RE, et al. Development of dendritic epidermal $\mathrm{T}$ cells with a skewed diversity of gamma delta TCRs in V delta 1-deficient mice. J Immunol. (2000) 165:3695705. doi: 10.4049/jimmunol.165.7.3695

27. Bonneville M, Itohara S, Krecko EG, Mombaerts P, Ishida I, Katsuki M, et al. Transgenic mice demonstrate that epithelial homing of gamma/delta $\mathrm{T}$ cells is determined by cell lineages independent of T cell receptor specificity. J Exp Med. (1990) 171:1015-26. doi: 10.1084/jem.171.4.1015

28. Mallick-Wood CA, Lewis JM, Richie LI, Owen MJ, Tigelaar RE, Hayday AC. Conservation of $\mathrm{T}$ cell receptor conformation in epidermal gammadelta cells with disrupted primary Vgamma gene usage. Science. (1998) 279:1729-33. doi: 10.1126/science.279.5357.1729

29. Edelbaum D, Mohamadzadeh M, Bergstresser PR, Sugamura K, Takashima A. Interleukin (IL)-15 promotes the growth of murine epidermal gamma delta $\mathrm{T}$ cells by a mechanism involving the beta- and gamma cchains of the IL-2 receptor. J Invest Dermatol. (1995) 105:837-43. doi: 10.1111/1523-1747.ep12326630

30. Li Y, Innocentin S, Withers DR, Roberts NA, Gallagher AR, Grigorieva EF, et al. Exogenous stimuli maintain intraepithelial lymphocytes via aryl hydrocarbon receptor activation. Cell. (2011) 147:629-40. doi: 10.1016/j.cell.2011.09.025

31. Zhang B, Wu J, Jiao Y, Bock C, Dai M, Chen B, et al. Differential requirements of TCR signaling in homeostatic maintenance and function of dendritic epidermal T cells. J Immunol. (2015) 195:4282-91. doi: 10.4049/jimmunol.1501220

32. Chodaczek G, Papanna V, Zal MA, Zal T. Body-barrier surveillance by epidermal $\gamma \delta$ TCRs. Nat Immunol. (2012) 13:272-82. doi: 10.1038/ni.2240

33. Girardi M, Lewis J, Glusac E, Filler RB, Geng L, Hayday AC, et al. Resident skin-specific gammadelta $\mathrm{T}$ cells provide local, nonredundant regulation of cutaneous inflammation. J Exp Med. (2002) 195:855-67. doi: 10.1084 /jem. 20012000

34. Jameson JM, Cauvi G, Witherden DA, Havran WL. A keratinocyte-responsive gamma delta TCR is necessary for dendritic epidermal T cell activation by damaged keratinocytes and maintenance in the epidermis. J Immunol. (2004) 172:3573-9. doi: 10.4049/jimmunol.172.6.3573

35. Havran WL, Chien YH, Allison JP. Recognition of self antigens by skinderived T cells with invariant gamma delta antigen receptors. Science. (1991) 252:1430-2. doi: 10.1126/science.1828619

36. Shiohara T, Moriya N, Hayakawa J, Itohara S, Ishikawa H. Resistance to cutaneous graft-vs.-host disease is not induced in T cell receptor delta genemutant mice. J Exp Med. (1996) 183:1483-9. doi: 10.1084/jem.183.4.1483

37. Komori HK, Witherden DA, Kelly R, Sendaydiego K, Jameson JM, Teyton $\mathrm{L}$, et al. Cutting edge: dendritic epidermal gammadelta $\mathrm{T}$ cell ligands are rapidly and locally expressed by keratinocytes following cutaneous wounding. J Immunol. (2012) 188:2972-6. doi: 10.4049/jimmunol.1100887

38. Witherden DA, Verdino P, Rieder SE, Garijo O, Mills RE, Teyton L, et al. The junctional adhesion molecule JAML is a costimulatory receptor for epithelial gammadelta T cell activation. Science. (2010) 329:1205-10. doi: 10.1126/science. 1192698

39. Witherden DA, Watanabe M, Garijo O, Rieder SE, Sarkisyan G, Cronin SJ, et al. The CD100 receptor interacts with its plexin B2 ligand to regulate epidermal gammadelta T cell function. Immunity. (2012) 37:314-25. doi: 10.1016/j.immuni.2012.05.026

40. Schuhmachers G, Ariizumi K, Mathew PA, Bennett M, Kumar V, Takashima A. 2B4, a new member of the immunoglobulin gene superfamily, is expressed on murine dendritic epidermal $\mathrm{T}$ cells and plays a functional role in their killing of skin tumors. J Invest Dermatol. (1995) 105:592-6. doi: 10.1111/1523-1747.ep12323533

41. Ibusuki A, Kawai K, Yoshida S, Uchida Y, Nitahara-Takeuchi A, Kuroki $\mathrm{K}$, et al. NKG2D triggers cytotoxicity in murine epidermal gammadelta $\mathrm{T}$ cells via PI3K-dependent, Syk/ZAP70-independent signaling pathway. J Invest Dermatol. (2014) 134:396-404. doi: 10.1038/jid.2013.353

42. Girardi M, Oppenheim DE, Steele CR, Lewis JM, Glusac E, Filler R, et al. Regulation of cutaneous malignancy by gammadelta T cells. Science. (2001) 294:605-9. doi: 10.1126/science.1063916
43. Jung H, Hsiung B, Pestal K, Procyk E, Raulet DH. RAE-1 ligands for the NKG2D receptor are regulated by E2F transcription factors, which control cell cycle entry. J Exp Med. (2012) 209:2409-22. doi: 10.1084/jem.20120565

44. Takashima A, Nixon-Fulton JL, Bergstresser PR, Tigelaar RE. Thy-1+ dendritic epidermal cells in mice: precursor frequency analysis and cloning of concanavalin A-reactive cells. J Invest Dermatol. (1988) 90:671-8. doi: 10.1111/1523-1747.ep12560835

45. Matsue H, Bergstresser PR, Takashima A. Keratinocyte-derived IL-7 serves as a growth factor for dendritic epidermal T cells in mice. J Immunol. (1993) 151:6012-9. doi: 10.1016/0923-1811(93)90782-K

46. Wang Y, Bai Y, Li Y, Liang G, Jiang Y, Liu Z, et al. IL-15 enhances activation and IGF-1 production of dendritic epidermal $t$ cells to promote wound healing in diabetic mice. Front Immunol. (2017) 8:1557. doi: 10.3389/fimmu.2017.01557

47. Zelante T, Fric J, Wong AY, Ricciardi-Castagnoli P. Interleukin-2 production by dendritic cells and its immuno-regulatory functions. Front Immunol. (2012) 3:161. doi: 10.3389/fimmu.2012.00161

48. Nitahara A, Shimura H, Ito A, Tomiyama K, Ito M, Kawai K. NKG2D ligation without $\mathrm{T}$ cell receptor engagement triggers both cytotoxicity and cytokine production in dendritic epidermal T cells. J Invest Dermatol. (2006) 126:1052-8. doi: 10.1038/sj.jid.5700112

49. Matsue H, Cruz PD Jr, Bergstresser PR, Takashima A. Profiles of cytokine mRNA expressed by dendritic epidermal T cells in mice. J Invest Dermatol. (1993) 101:537-42. doi: 10.1111/1523-1747.ep12365917

50. Ryu TH, Kye H, Choi JE, Ahn HH, Kye YC, Seo SH. Features causing confusion between basal cell carcinoma and squamous cell carcinoma in clinical diagnosis. Ann Dermatol. (2018) 30:64-70. doi: 10.5021/ad.2018.30.1.64

51. Ratushny V, Gober MD, Hick R, Ridky TW, Seykora JT. From keratinocyte to cancer: the pathogenesis and modeling of cutaneous squamous cell carcinoma. J Clin Invest. (2012) 122:464-72. doi: 10.1172/JCI57415

52. Martinez VD, Becker-Santos DD, Vucic EA, Lam S, Lam WL. Induction of human squamous cell-type carcinomas by arsenic. J Skin Cancer. (2011) 2011:454157. doi: 10.1155/2011/454157

53. Pfeifer GP, Besaratinia A. UV wavelength-dependent DNA damage and human non-melanoma and melanoma skin cancer. Photochem Photobiol Sci. (2012) 11:90-7. doi: 10.1039/C1PP05144J

54. Stanoszek LM, Wang GY, Harms PW. Histologic mimics of basal cell Carcinoma. Arch Pathol Lab Med. (2017) 141:1490-502. doi: 10.5858/arpa.2017-0222-RA

55. Black AP, Ogg GS. The role of p53 in the immunobiology of cutaneous squamous cell carcinoma. Clin Exp Immunol. (2003) 132:379-84. doi: 10.1046/j.1365-2249.2003.02159.x

56. Kaminski MJ, Cruz PD Jr, Bergstresser PR, Takashima A. Killing of skinderived tumor cells by mouse dendritic epidermal T-cells. Cancer Res. (1993) 53:4014-9.

57. Cavanagh LL, Barnetson RS, Basten A, Halliday GM. Dendritic epidermal Tcell involvement in induction of CD8 $+\mathrm{T}$ cell-mediated immunity against an ultraviolet radiation-induced skin tumor. Int J Cancer. (1997) 70:98105. doi: 10.1002/sici1097-02151997010670:198::aid-ijc153.0.co;2-9

58. Macleod AS, Rudolph R, Corriden R, Ye I, Garijo O, Havran WL. Skin-resident $\mathrm{T}$ cells sense ultraviolet radiation-induced injury and contribute to DNA repair. J Immunol. (2014) 192:5695-702. doi: 10.4049/jimmunol.1303297

59. Wang L, Yi T, Zhang W, Pardoll DM, Yu H. IL-17 enhances tumor development in carcinogen-induced skin cancer. Cancer Res. (2010) 70:10112-20. doi: 10.1158/0008-5472.CAN-10-0775

60. Chen X, Cai G, Liu C, Zhao J, Gu C, Wu L, et al. IL-17R-EGFR axis links wound healing to tumorigenesis in Lrig1(+) stem cells. J Exp Med. (2019) 216:195-214. doi: 10.1084/jem.20171849

61. Fabre J, Giustiniani J, Garbar C, Antonicelli F, Merrouche Y, Bensussan A, et al. Targeting the tumor microenvironment: the protumor effects of IL-17 related to Cancer type. Int J Mol Sci. (2016) 17:1433. doi: 10.3390/ijms170 91433

62. Rei M, Goncalves-Sousa N, Lanca T, Thompson RG, Mensurado S, Balkwill FR, et al. Murine CD27(-) $\mathrm{V} \gamma 6(+) \gamma \delta \mathrm{T}$ cells producing IL17A promote ovarian cancer growth via mobilization of protumor small peritoneal macrophages. Proc Natl Acad Sci USA. (2014) 111:E3562-70. doi: $10.1073 /$ pnas. 1403424111 
63. Daley D, Zambirinis CP, Seifert L, Akkad N, Mohan N, Werba G, et al. $\gamma \delta \mathrm{T}$ cells support pancreatic oncogenesis by restraining $\alpha \beta \mathrm{T}$ cell activation. Cell. (2016) 166:1485-99.e15. doi: 10.1016/j.cell.2016.07.046

64. Hinrichs CS, Kaiser A, Paulos CM, Cassard L, Sanchez-Perez L, Heemskerk B, et al. Type 17 CD8+ T cells display enhanced antitumor immunity. Blood. (2009) 114:596-9. doi: 10.1182/blood-2009-02-203935

65. Ma Y, Aymeric L, Locher C, Mattarollo SR, Delahaye NF, Pereira P, et al. Contribution of IL-17-producing gamma delta $\mathrm{T}$ cells to the efficacy of anticancer chemotherapy. J Exp Med. (2011) 208:491-503. doi: 10.1084 /jem. 20100269

66. Martin-Orozco N, Muranski P, Chung Y, Yang XO, Yamazaki T, Lu S, et al. $\mathrm{T}$ helper 17 cells promote cytotoxic $\mathrm{T}$ cell activation in tumor immunity. Immunity. (2009) 31:787-98. doi: 10.1016/j.immuni.2009.09.014

67. Cavanagh LL, Halliday GM. Dendritic epidermal T cells in ultravioletirradiated skin enhance skin tumor growth by inhibiting CD4+ T-cellmediated immunity. Cancer Res. (1996) 56:2607-15.

68. Dao V, Liu Y, Pandeswara S, Svatek RS, Gelfond JA, Liu A, et al. Immunestimulatory effects of rapamycin are mediated by stimulation of antitumor $\gamma \delta$ T Cells. Cancer Res. (2016) 76:5970-82. doi: 10.1158/0008-5472.CAN16-0091

69. Nielsen MM, Dyring-Andersen B, Schmidt JD, Witherden D, Lovato P, Woetmann A, et al. NKG2D-dependent activation of dendritic epidermal T cells in contact hypersensitivity. J Invest Dermatol. (2015) 135:1311-9. doi: $10.1038 /$ jid.2015.23

70. Strid J, Roberts SJ, Filler RB, Lewis JM, Kwong BY, Schpero W, et al. Acute upregulation of an NKG2D ligand promotes rapid reorganization of a local immune compartment with pleiotropic effects on carcinogenesis. Nat Immunol. (2008) 9:146-54. doi: 10.1038/ni1556

71. Strid J, Sobolev O, Zafirova B, Polic B, Hayday A. The intraepithelial T cell response to NKG2D-ligands links lymphoid stress surveillance to atopy. Science. (2011) 334:1293-7. doi: 10.1126/science.1211250

72. Whang MI, Guerra N, Raulet DH. Costimulation of dendritic epidermal gammadelta $\mathrm{T}$ cells by a new NKG2D ligand expressed specifically in the skin. J Immunol. (2009) 182:4557-64. doi: 10.4049/jimmunol.08 02439

73. Nixon-Fulton JL, Hackett J Jr, Bergstresser PR, Kumar V, Tigelaar RE. Phenotypic heterogeneity and cytotoxic activity of Con A and IL-2-stimulated cultures of mouse Thy-1+ epidermal cells. J Invest Dermatol. (1988) 91:62-8. doi: 10.1111/1523-1747.ep12463290

74. Huber H, Descossy P, van Brandwijk R, Knop J. Activation of murine epidermal TCR-gamma delta $+\mathrm{T}$ cells by keratinocytes treated with contact sensitizers. J Immunol. (1995) 155:2888-94.

75. Garni-Wagner BA, Purohit A, Mathew PA, Bennett M, Kumar V. A novel function-associated molecule related to non-MHC-restricted cytotoxicity mediated by activated natural killer cells and $\mathrm{T}$ cells. J Immunol. (1993) 151:60-70.

76. Sentman CL, Hackett J Jr, Moore TA, Tutt MM, Bennett M, Kumar V. Pan natural killer cell monoclonal antibodies and their relationship to the NK1.1 antigen. Hybridoma. (1989) 8:605-14. doi: 10.1089/hyb.1989.8.605

77. Love-Schimenti CD, Kripke ML. Inhibitory effect of a dendritic epidermal T cell line on K1735 melanoma cells in vivo and in vitro. J Leukoc Biol. (1994) 55:379-84. doi: 10.1002/jlb.55.3.379

78. Champsaur M, Lanier LL. Effect of NKG2D ligand expression on host immune responses. Immunol Rev. (2010) 235:267-85. doi: $10.1111 / \mathrm{j} .0105-2896.2010 .00893 . \mathrm{x}$

Conflict of Interest: The authors declare that the research was conducted in the absence of any commercial or financial relationships that could be construed as a potential conflict of interest.

Copyright (c) 2020 Xiang, Qiu and Zhang. This is an open-access article distributed under the terms of the Creative Commons Attribution License (CC BY). The use, distribution or reproduction in other forums is permitted, provided the original author(s) and the copyright owner(s) are credited and that the original publication in this journal is cited, in accordance with accepted academic practice. No use, distribution or reproduction is permitted which does not comply with these terms. 